\title{
Nematode extraction from banana roots by the centrifugal- flotation technique
}

Jean-Louis SARAH ${ }^{1 *}$, Marc BoIsSEAU ${ }^{2}$

${ }^{1}$ CIRAD, blvd. La Lironde, TA A-DIR/PS3, 34398 Montpellier Cedex 5, France

jean-louis.sarah@cirad.fr

${ }^{2}$ CIRAD, UPR Multiplication végétative, Station de Roujols, Petit Bourg, 97170,

Guadeloupe, France

marc.boisseau@cirad.fr

\author{
Nematode extraction from banana roots by the centrifugal-flotation \\ technique.
}

Abstract - Introduction. The centrifugal-flotation technique allows all nematode species and life stages to be separated from root debris and residual soil particles to facilitate their observation. The principle of the method applied, key advantages, starting plant material and time required are presented. Materials and methods. Necessary laboratory materials, and details of the 19 steps required for extracting nematodes from plant tissue for counting are described. Possible troubleshooting is explained.

France (Guadeloupe) / Musa sp. / pest control / methods / extraction / laboratory equipment / plant nematodes / cell counting

\section{Extraction de nématodes à partir de racines de bananiers par la technique de centrifugation-flottaison.}

Résumé - Introduction. La technique de centrifugation-flottaison permet de séparer toutes les espèces de nématodes, à tous les stades de développement, des particules de sol restant et des débris de racine pour faciliter leur observation. Le principe de la méthode appliquée, les principaux avantages, le matériel végétal nécessaire et le temps requis sont présentés. Matériel et méthodes. Le matériel de laboratoire nécessaire, ainsi que le détail des 19 étapes utilisées pour extraire les nématodes à partir du tissu végétal avant dénombrement et détermination sont décrits. Les problèmes potentiels sont répertoriés.

France (Guadeloupe) / Musa sp. / lutte antiravageur / méthode / extraction / matériel de laboratoire / nématode des plantes / numération cellulaire

\section{Introduction}

\section{Application}

Nematodes must be extracted from plant tissue for counting and identification of species. The centrifugal-flotation technique allows all nematode species and life stages to be separated from root debris and residual soil particles to facilitate their observation.

Fruits, 2008, vol. 63, p. 249-251 (C) 2008 Cirad/EDP Sciences All rights reserved DOI: 10.1051/fruits:2008018 www.fruits-journal.org

\section{Principle}

This method has been adapted to bananas from the centrifugal-flotation technique described by Coolen and d'Herde [1]. Root tissues are macerated in a kitchen blender.
The suspension of nematodes, plant debris and residual soil particles is poured on a sieve column and then abundantly washed. The biggest debris is retained by the upper sieve and discarded. The smallest debris is eliminated through the mesh of the last sieve. Residues are gently washed in a 500$\mathrm{mL}$ centrifuge tube. After a first centrifugation, the supernatant (water and the lightest debris) is discarded. The centrifuge tube is then filled with a solution of $\mathrm{MgSO}_{4}$ at a density similar to that of nematodes. After the second centrifugation, the supernatant containing only nematodes is collected on a 5- $\mu \mathrm{m}$ aperture sieve. Finally, nematodes are collected in a beaker or a test tube for counting 


\section{Key advantages}

This method:

- facilitates observation and counting since nematodes are collected in a suspension free of root debris,

- allows the collection of all nematodes and life stages (including eggs) whatever their mobility,

- saves time, since nematodes can be counted less than $1 \mathrm{~h}$ after the beginning of the extraction process.

\section{Starting material}

The method requires root samples collected in the field or from pots (greenhouse experiments).

\section{Time required}

About 40-50 min are necessary for four root samples ready to count. One person can extract and count about 16-20 samples a day.

\section{Materials and methods}

\section{Laboratory materials}

The method requires: a centrifuge with four 500-mL tubes (at least $250 \mathrm{~mL}$ ), a kitchen blender, a vibro-mixer, a set of sieves (at least three) with decreasing mesh aperture (e.g., $250 \mu \mathrm{m}, 50 \mu \mathrm{m}$, and $32 \mu \mathrm{m}$ or $25 \mu \mathrm{m}$ ), four sieves (as many as centrifuge tubes) of $5 \mu \mathrm{m}$-mesh aperture, a weighing balance, four funnels (as many as centrifuge tubes) adapted to centrifuge tube size, beakers, graduated tubes $(200 \mathrm{~mL})$ or any graduated glass vessel (e.g., beaker), a solution of $\mathrm{MgSO}_{4}$ at $1.16-1.17 \mathrm{~g} \cdot \mathrm{L}^{-1}$, kaolin and counting cells $(1 \mathrm{~mL})$.

\section{Protocol}

- Step 1

Wash crude root samples thoroughly to eliminate any soil residue.

- Step 2

Chop roots into $0.5-1-\mathrm{cm}$ sections.
- Step 3

Wash roots again to eliminate any residual soil particles.

\section{- Step 4}

Mix root sections thoroughly to prepare the aliquot sampling.

- Step 5

Sample an aliquot part of $50 \mathrm{~g}$ of root sections.

- Step 6

Pour the root aliquot into a kitchen blender with $200 \mathrm{~mL}$ of tap water. Macerate twice for $10 \mathrm{~s}$ with a 5-s pause.

- Step 7

Pour the macerated suspension into the column of sieves. Rinse the blender vessel thoroughly to collect all nematodes.

- Step 8

Wash the sieve column abundantly for $1 \mathrm{~min}$ (avoiding any splashing).

- Step 9

Discard residues on the top sieve $(250 \mu \mathrm{m})$.

- Step 10

Gently wash the intermediate sieve $(50 \mu \mathrm{m})$, giving it a $45^{\circ}$ slope and orientating the water flow from below to avoid as much as possible any nematode loss through the meshes. Make all residues flow down along the slope and accumulate along the lower part of the sieve edge.

Note: proceed above the $32 \mu \mathrm{m}$ (or $25 \mu \mathrm{m}$ ) sieve as a security against any casual nematode loss.

\section{- Step 11}

Pour residues through a funnel into the centrifuge tube. Wash gently and thoroughly with a washing bottle to collect all residues.

- Step 12

Repeat steps 10 and 11 with the lowest sieve (32 $\mu \mathrm{m}$ or $25 \mu \mathrm{m})$.

\section{- Step 13}

Add $15 \mathrm{~g}$ of kaolin to all centrifuge tubes. Mix the suspension with a vibro-mixer and balance the centrifuge tubes. 
Note: kaolin allows the residue to cement during the centrifugation for easier elimination of supernatant.

\section{- Step 14}

Proceed to a first centrifugation (1500 $\mathrm{g}$ for $5 \mathrm{~min}$ ) and discard the supernatant (water + the lightest root debris).

\section{- Step 15}

Fill the centrifuge tube with the $\mathrm{MgSO}_{4}$ solution. Put the residues and the kaolin in suspension again with the vibro-mixer and balance the tubes (using the $\mathrm{MgSO}_{4}$ solution). Note: this step is crucial. Make sure that the cemented kaolin is well resuspended, since nematodes could be trapped in kaolin curds.

- Step 16

Proceed to a second centrifugation (1500 g for $5 \mathrm{~min}$ ).

\section{- Step 17}

Collect nematodes:

- collect the supernatant containing nematodes on a sieve of $5-\mu \mathrm{m}$ aperture,

- wash gently to eliminate the saline solution residue,

- wash out nematodes into a graduated tube and adjust the volume of the suspension (generally $100 \mathrm{~mL}$ ) for counting.

Caution: carry out steps 15 to 17 very quickly since the osmotic pressure may destroy nematodes if they stay too long in the solution.

\section{- Step 18}

Put $1 \mathrm{~mL}$ of nematode suspension on a counting cell. Counting is done under a microscope or a binocular lens. For one root sample, counting must be repeated at least three times with $1 \mathrm{~mL}$.

Caution: nematodes decant progressively in the tube; don't forget to shake the tube thoroughly before taking the $1-\mathrm{mL}$ sample.

- Step 19

Results are expressed as density of nematodes per $\mathrm{g}$ of root.

\section{Troubleshooting}

Four main problems can occur. (a) No or few observed nematodes out of an apparently infested root sample. This can result from:

- A density of $\mathrm{MgSO}_{4}$ solution under $1.16 \mathrm{~g} \cdot \mathrm{L}^{-1}$.

Solution: check the solution density before proceeding.

- Remaining kaolin curds after the vibromixing phase of the second centrifugation (step 16).

Solution: make sure the cemented kaolin is finely divided and well suspended in the solution.

- Nematodes decanted in the tube before counting.

Solution: thoroughly shake the tube before taking the 1-ml sample (step 18).

(b) Nematodes are distorted and not identifiable. This can result from:

- A density of MgSO4 solution over $1.17 \mathrm{~g} \cdot \mathrm{L}^{-1}$.

Solution: check the solution density before proceeding.

- A correct density of $\mathrm{MgSO}_{4}$ solution but nematodes stayed too long in it.

Solution: proceed very rapidly during steps 15 to 17 when nematodes are suspended in the solution.

(c) Many root fragments are in the counting suspension: this may be due to a density of $\mathrm{MgSO}_{4}$ solution which was over $1.17 \mathrm{~g} \cdot \mathrm{L}^{-1}$. Solution: check the solution density before proceeding.

(d) Many chopped nematodes are in the counting suspension: this may be due to too high a speed or too long a running-time of maceration (step 6).

Solution: adjust these parameters to the model of the blender used.

\section{References}

[1] Coolen W.A., d'Herde C.J., A method for the quantitative extraction of nematodes from plant tissue, Ghent State Agric. Res. Cent., Ghent, Belgium, 1972, $77 \mathrm{p}$. 